\title{
Effect of Al on the Long-Term Oxidation Behavior of Fe-0.5C Alloys
}

\author{
V. Shankar Rao and V. S. Raja * \\ Corrosion Science and Engineering Program \\ Indian Institute of Technology, Bombay, Mumbai-400 076, India
}

(Received April 1, 2002)

\begin{abstract}
Electroslag remelted cast iron-aluminum alloys having the compositions: 1) Fe-16Al-0.5C, 2) Fe-10Al$0.5 \mathrm{C}$, and 3) $\mathrm{Fe}-8 \mathrm{Al}-0.5 \mathrm{C}$ were employed to investigate the effect of $\mathrm{Al}$ on the oxidation behavior of $\mathrm{Fe}-0.5 \mathrm{C}$ alloys in the temperature range $973-1273 \mathrm{~K}$. Microstructural and phase analyses of these alloys revealed distribution of a carbide phase, $\mathrm{Fe}_{3} \mathrm{AlC}_{0,692}$ in the $\mathrm{Fe}_{3} \mathrm{Al}$ matrix of alloy 1 and in $\mathrm{Fe}-\mathrm{Al}$ matrix of alloys 2 and 3. The oxidation behavior of these alloys was found to be dependent upon relative composition and stability of the carbide and matrix phases. High-Al content alloys were free from decarburization, whereas low-Al content alloys suffered from decarburization.
\end{abstract}

\section{INTRODUCTION}

There has been an increasing number of studies, in recent years, on the development of carbon containing iron aluminides for high-temperature applications /1-5/. This is because of the two-fold benefits carbon is reported to offer for iron aluminides. By enabling carbide formation, it offers strength to this material on one hand and reduces the environmental embrittlement on the other $/ 1,5,6 /$. Yet another means of reducing the brittleness of iron aluminides is to bring down the $\mathrm{Al}$ content $17,8 \%$. However, both these modifications may have a bearing on the oxidation resistance of these materials, a property vital for their successful hightemperature applications. The oxidation behavior of FeAl alloys has been well documented by several investigators $19-13 /$, whereas reports on the oxidation behavior of Fe-Al-C alloys are few $/ 14,16,17 /$. The understanding of oxidation behavior of binary Fe-Al alloys is itself complex; the addition of $\mathrm{C}$ makes this even more complicated as it modifies the microstructure of the alloy. In view of these facts the present study gains importance.

The first ever work on the oxidation behavior of carbon containing $\mathrm{Fe}-\mathrm{Al}$ alloy reported in literature is by Boggs $/ 15 \%$. He reported an increase in oxidation rate at $1073 \mathrm{~K}$ with increase in carbon content from 0.05 to $0.1 \mathrm{C}$ in $\mathrm{Fe}-4.94 \mathrm{Al}$ alloys, which was attributed to the growth of nodular iron oxide through the alumina film. The frequency with which the nodules penetrated the alumina layer increased with increasing carbon concentration. Kao and Wan investigated the effect of temperature on the oxidation behavior of Fe-5.5Al$0.55 \mathrm{C}$ alloy at 873,1073 and $1273 \mathrm{~K}$ and showed that temperature strongly influences the oxidation of the carbide phase $/ 16 /$. Further investigation by the same authors of $\mathrm{Fe}-7.5 \mathrm{Al}-0.65 \mathrm{C}$ alloy showed internal oxidation of $\mathrm{Al}$ beneath the iron oxide nodules at $873 \mathrm{~K}$, which is eliminated at temperatures $973-1173 \mathrm{~K} / 18$.

\footnotetext{
* Corresponding author Fax; +91-22-572-3480

E-mail address: vsraja@met.iitb.ac.in
} 
The role of carbon on oxidation behavior of $\mathrm{Fe}_{3} \mathrm{Al}$ based iron aluminides has been examined in our previous work $/ 14 /$. In that study, no adverse effect of $\mathrm{C}$ was found on oxidation tendency of these iron aluminides between $973-1173 \mathrm{~K}$ when $\mathrm{C}$ lay in the range of $0.05-1$ $w t \%$. In another contemporary study, it was shown that addition of $1 \mathrm{wt} \% \mathrm{C}$ was detrimental to oxidation resistance of Fe-xAl-IC alloys especially in low-Al content alloys $/ 14 /$. Therefore, Fe-Al alloys were produced by reducing the $\mathrm{C}$ content from $1 \mathrm{wt} \%$ to $0.5 w t \%$ with a view to developing good oxidation resistance alloys.

\section{MATERIALS}

These iron-aluminum alloys were prepared by air induction melting and subsequently processed through electro slag refining process. The nominal compositions of the alloys in wt $\%$ are: 1) Fe-16Al-0.5C, 2) Fe-10Al$0.5 \mathrm{C}$ and 3) Fe-8Al-0.5C. Details on processing technology and mechanical properties can be found elsewhere /19-21/. All these alloys, under present study, are in the cast form. The selection of these alloys should enable understanding of the role of $\mathrm{Al}$ in the oxidation behavior of iron-aluminum alloys containing $0.5 \% \mathrm{C}$.

\section{EXPERIMENTAL}

\section{Microstructural and Phase Analysis}

Samples for optical microscopy were obtained by polishing them on various grades of $\mathrm{SiC}$ papers starting from 220 to 800 followed by diamond polishing and then etching. The etchant consisted of $33 \% \mathrm{CH}_{3} \mathrm{COOH}+$ $33 \% \mathrm{HNO}_{3}+1 \% \mathrm{HF}+33 \% \mathrm{H}_{2} \mathrm{O}$ by volume. The microstructures of the alloys were examined using a Leica, Reichert MeF3A optical microscope. X-ray diffraction (XRD) studies were carried out to identify the phases using Philips PW-1820 diffractometer. Various phases were identified using PCDFWIN powder diffraction software package.

\section{Oxidation Studies}

The specimens used for oxidation test were $12 \times 12$ x $4 \mathrm{~mm}$ in size. Samples for oxidation study were obtained by polishing them on successive grades of $\mathrm{SiC}$ paper up to 800 . Prior to the commencement of oxidation, specimens were ultrasonically cleaned using acetone, dried, and finally weighted. Oxidation studies were carried out by exposing the samples to stagnant air in a resistance-heated tubular furnace controlled with an accuracy of $\pm 5 \mathrm{~K}$. Experiments were conducted in duplicate to check for reproducibility of data. The weight change of the specimens was recorded at regular intervals of $25 \mathrm{~h}$. A semi microbalance having an accuracy of $1 \times 10^{-5} \mathrm{gm}$ was used. Crystal structures of the oxide scale formed on the alloys were determined by XRD technique as described in the previous section. The surface morphology and cross-sectional view of oxide-scale were examined by using scanning-electron microscope (SEM) and energy depressive $x$-ray (EDX) was used to analyze their composition.

\section{RESULTS}

\section{Microstructural and Phase Analysis}

Microstructures of alloys 1-3, as seen on an optical microscope, are presented in Fig. 1. The dark contrast area delineates carbide phase, while the light contrast area corresponds to the matrix. Alloy 1 having $16 \mathrm{wt} \%$ $\mathrm{Al}$ exhibits elongated second phase particles of carbide distributed in the matrix as shown in Fig. la, whereas alloy 2 with $10 \mathrm{wt} \% \mathrm{Al}$ displays spherical carbide particles (Fig. Ib). In the latter case (Fig. Ib) carbides are more uniformly distributed compared to the former (Fig. 1a). On reducing the $\mathrm{Al}$ content from 10 to $8 \mathrm{wt} \%$, the morphology of the carbides changes to a needle-like shape, as shown in Fig. Ic. Since the carbon content is the same in all the alloys, the difference in microstructure can be attributed to the variation in $\mathrm{Al}$ content.

XRD patterns obtained for alloys 1 and 3 at ambient temperature are shown in Fig. 2. The $d$-values and lattice parameters obtained from the patterns are summarized in Table 1. For comparison, the lattice parameter of the phases reported in JCPDS files are also 


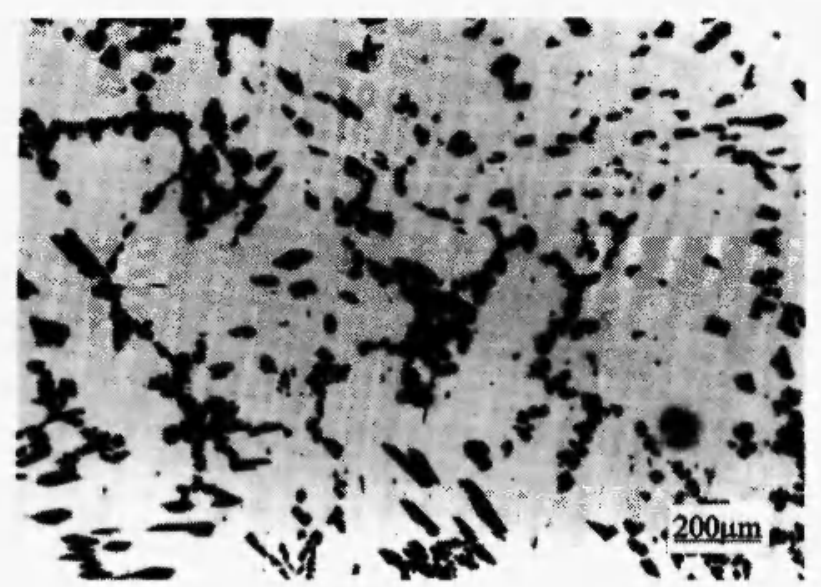

(a)

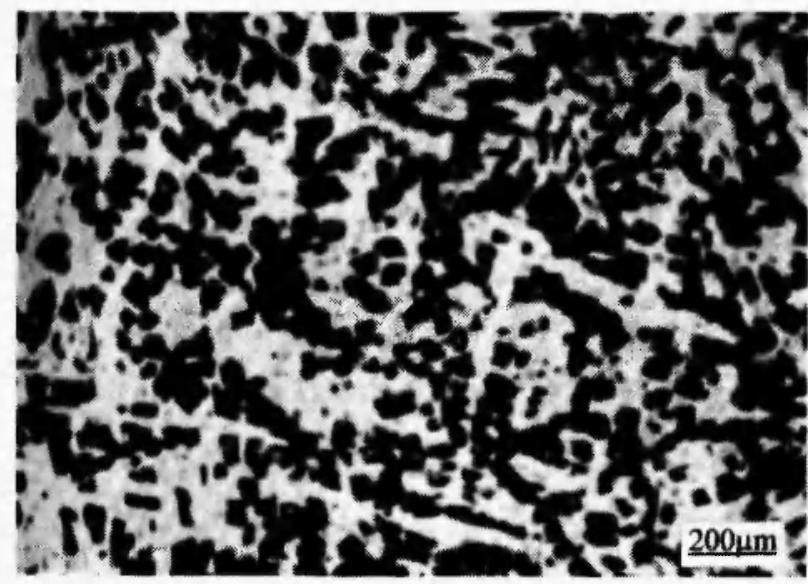

(b)

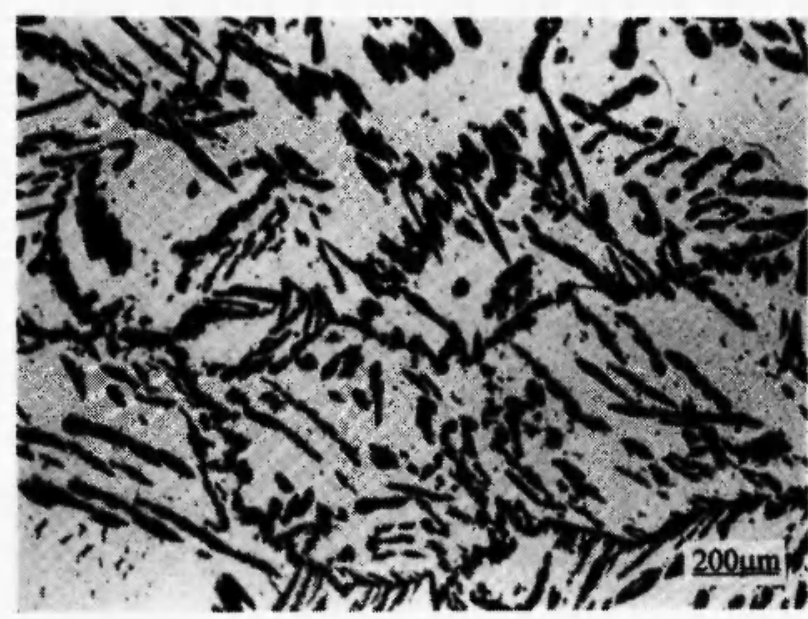

(c)

Fig. 1: Optical microstructures: a) alloy 1 shows elongated carbide particles, b) alloy 2 shows spherical carbide particles and c) alloy 3 shows needle-like shape carbide particles. shown. For alloy 1, having the $\mathrm{Al}$ content of $16-\mathrm{wt} \%$, peaks corresponding to $\mathrm{Fe}_{3} \mathrm{Al}$ and $\mathrm{Fe}_{3} \mathrm{AlC}_{069}$ are seen (Fig. 2a). As indicated by Fig. 2b, the XRD pattern for alloy 3 reveals peaks of $\alpha$ (Fe-Al) and $\mathrm{Fe}_{3} \mathrm{AlC}_{0.69}$ phases. $\mathrm{Fe}_{3} \mathrm{Al}$ has bcc, whereas $\mathrm{Fe}_{3} \mathrm{AlC}_{0.69}$ exhibits fcc perovskite-type structure. In all the alloys carbide phase is present with the same stoichiometry of $\mathrm{Fe}_{3} \mathrm{AlC}_{069}$ as reflected in lattice parameter. Since the XRD patterns shown here correspond to the sheet sample of as cast alloys used for the oxidation studies, they do not exactly correspond to powder patterns. The peak intensities of various planes do not match with the reported intensity of the corresponding planes by JCPDS files. These variations could occur due to possible preferential orientation of phases in the cast alloy. Furthermore, the lattice parameter of $\mathrm{Fe}_{3} \mathrm{Al}$ in the present alloy is higher than that reported in JCPDS files, implying that carbon is soluble in $\mathrm{Fe}_{3} \mathrm{Al}$ phase even at room temperature. As per $\mathrm{Fe}-\mathrm{Al}$ phase diagram, alloys with $16 \mathrm{wt} \% \mathrm{Al}$ show $\mathrm{Fe}_{3} \mathrm{Al}$ stoichiometry, the alloys with $10 \mathrm{wt} \% \mathrm{Al}$ exhibit dual phase region $\left(\mathrm{Fe}_{3} \mathrm{Al}+\infty\right)$, whereas the alloys with 8 wt\% Al fall in the single phase region of $\propto \mathrm{Fe}-\mathrm{Al} / 22 /$. With the introduction of carbon in these alloys depletion of $\mathrm{Al}$ in the matrix occurs due to the formation of $\mathrm{Fe}_{3} \mathrm{AlC}_{069}$ intermetallic phase. In turn, this may cause transition of $\mathrm{Fe}_{3} \mathrm{Al}$ phase to $\propto$.

\section{Kinetics}

The oxidation kinetic of alloys 1-3 was studied at four different temperatures, viz. 973, 1073, 1173, and $1273 \mathrm{~K}$. Figs. 3a-d show the variation in the weight gain per unit area as a function of time for different temperatures. Alloy 3 exhibits higher oxidation rate than the alloys 1 and 2 at all the temperatures under study. At $973 \mathrm{~K}$ the weight gain follows the order of alloy $3>$ alloy $2>$ alloy 1 , while at $1073 \mathrm{~K}$ the weight gain follows the order of alloy $3>$ alloy $2 \approx$ alloy 1 . On raising the temperature to $1173 \mathrm{~K}$ there is not much increase in weight gain in alloys 1 and 2, whereas alloy 3 exhibits an increase in weight gain by more than two times. When the temperature is further increased to $1273 \mathrm{~K}$, a marginal drop in weight gain occurs in the case of alloy 1 , whereas alloys 2 and 3 display continuous increase in weight gain. Notably, at this temperature, alloys 1 and 2 follow the same kinetics up 


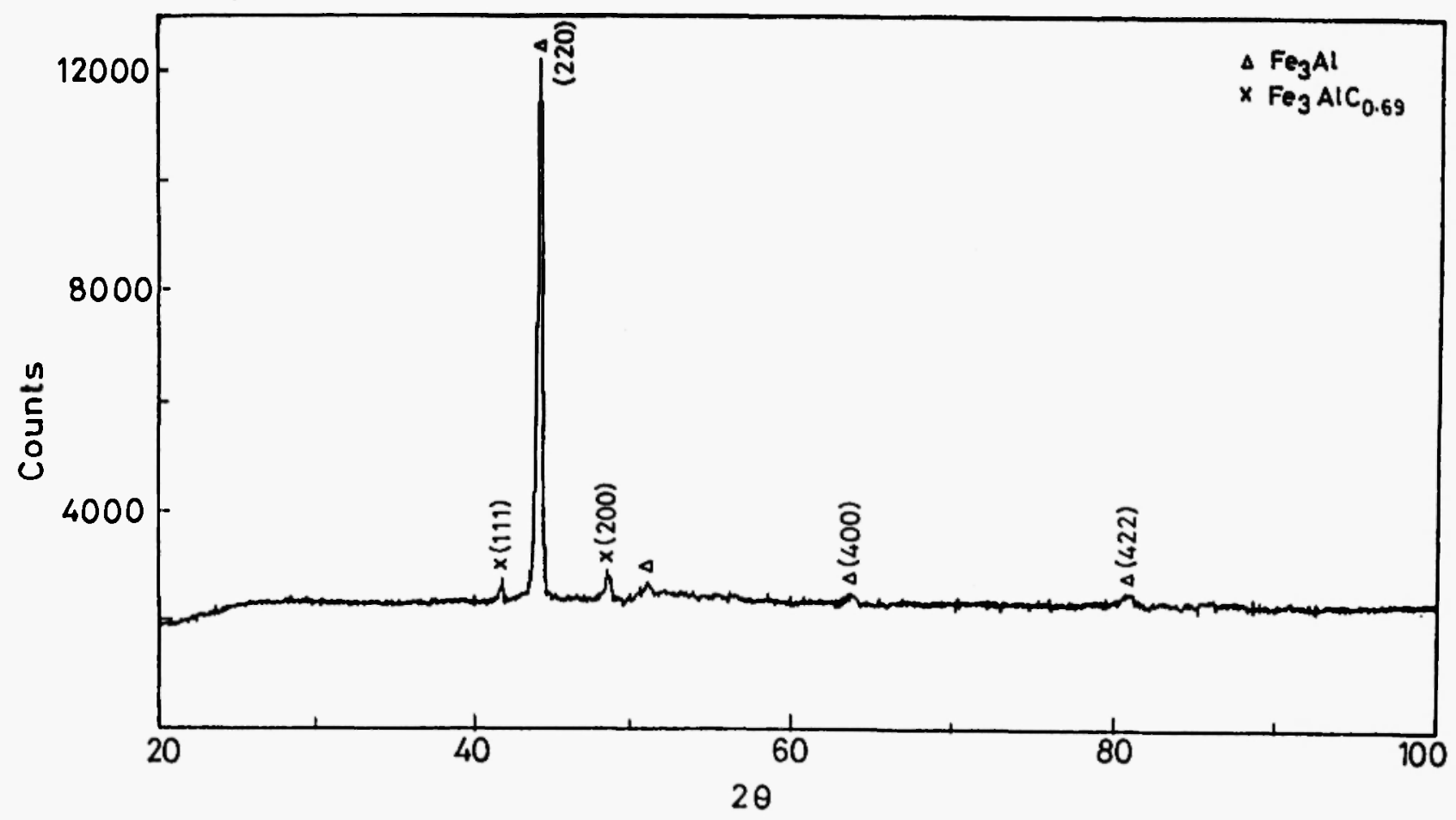

(a)

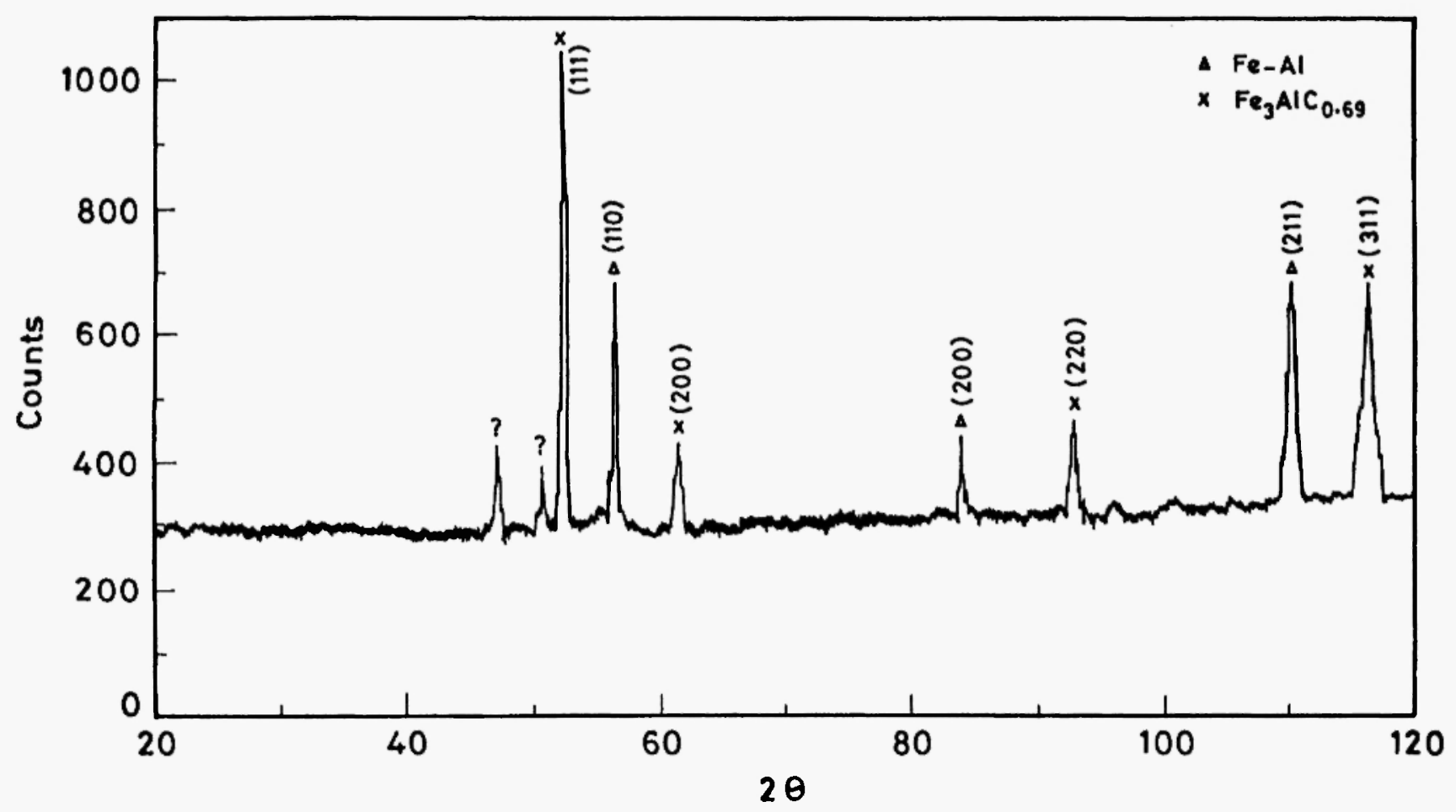

(b)

Fig. 2: X-ray diffraction patterns of a) alloy 1 and b) alloy 3 . 
Table 1

Summary of XRD data of alloys 1 and 3 obtained from Figs. 2a-b

\begin{tabular}{|c|c|c|c|c|c|c|c|c|}
\hline Alloy & $\begin{array}{r}d \text {-value } \\
\text { [nm] }\end{array}$ & $\begin{array}{l}\text { Plane } \\
\text { (hkl) }\end{array}$ & $\begin{array}{c}\text { I/Io } \\
\text { (Obs.) }\end{array}$ & $\begin{array}{l}\text { I/Io } \\
\text { (Ref) }\end{array}$ & \multicolumn{2}{|c|}{$\begin{array}{l}\text { Cell parameter }[\mathrm{nm}] \\
\quad(\text { Calc. }) \text { (Ref.) }\end{array}$} & Phase & $\begin{array}{l}\text { JCPDS } \\
\text { Card No. }\end{array}$ \\
\hline \multirow[t]{6}{*}{1} & 0.205 & 220 & 100 & 100 & $\mathrm{a}=0.582$ & $\mathrm{a}=0.579$ & $\mathrm{Fe}_{3} \mathrm{Al}$ & $06-0695$ \\
\hline & 0.180 & - & 0.9 & 20 & & & & \\
\hline & 0.146 & 400 & 0.6 & 80 & & & & \\
\hline & 0.118 & 422 & 2.0 & 90 & & & & \\
\hline & 0.216 & 111 & 3.3 & 100 & $a=0.377$ & $a=0.377$ & $\mathrm{Fe}_{3} \mathrm{AlC}_{0.69}$ & 03-0965 \\
\hline & 0.188 & 200 & 4.9 & 80 & & & & \\
\hline \multirow[t]{7}{*}{3} & 0.204 & 110 & 48.5 & 100 & $a=0.286$ & 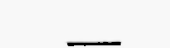 & Fe-Al & $06-0696$ \\
\hline & 0.145 & 200 & 10.6 & 20 & & & & \\
\hline & 0.118 & 211 & 32.5 & 30 & & & & \\
\hline & 0.218 & 111 & 100 & 100 & $a=0.377$ & $a=0.377$ & $\mathrm{Fe}_{3} \mathrm{AlC}_{0.69}$ & $03-0965$ \\
\hline & 0.189 & 200 & 16.3 & 80 & & & & \\
\hline & 0.133 & 220 & 19.7 & 80 & & & & \\
\hline & 0.114 & 311 & 34.6 & 80 & & & & \\
\hline
\end{tabular}

to $300 \mathrm{~h}$. On further oxidation, alloy 1 displays weight loss in steps and reaches almost its initial weight, while alloy 2 displays a continuous increase in weight. A rapid weight gain in alloy 3 at $1273 \mathrm{~K}$ after $100 \mathrm{~h}$ of oxidation possibly reflects the breakaway oxidation.

With temperature, the oxidation tendency of alloy 1 varies in the following order: $973<1073<1273<1173$ K. Alloys 2 and 3 follow the order $1073<1173<1273$ $<973 \mathrm{~K}$. The difference in weight gain due to inversion of oxidation between $973-1073 \mathrm{~K}$ in alloy 2 is 0.37 $\mathrm{mg} / \mathrm{cm}^{2}$ whereas in the case of alloy 3 it is 11.50 $\mathrm{mg} / \mathrm{cm}^{2}$, which is more than thirty times. This oxidation inversion has been discussed with respect to Fe-xAl-IC and it was attributed to the preferential oxidation of $\mathrm{Al}$ at $1073 \mathrm{~K} / 14$.

\section{Oxide Scale Characterization}

Morphologies of the oxide-scale viewed in SEM are shown in Figs. 4 to 6. A micrograph of alloy 1 oxidized at $1173 \mathrm{~K}$ for $1000 \mathrm{~h}$ is presented in Fig. 4. The oxidescale on this alloy appears to have not developed uniformly, which created grooves in the oxide-scales. This is possibly due to different oxide growth rates on matrix and carbide phases. The oxide-scale formed on alloy 2 at $1273 \mathrm{~K}$ after $1000 \mathrm{~h}$ of oxidation is shown in Fig. 5. Here, though oxide-scale is uniform, it shows some platelet-like crystals of oxide in the scale. A micrograph of alloy 3 oxidized at $973 \mathrm{~K}$ for $100 \mathrm{~h}$ is shown in Fig. 6a. The oxides appear as whiskers and even after $100 \mathrm{~h}$ of oxidation the surface is not 

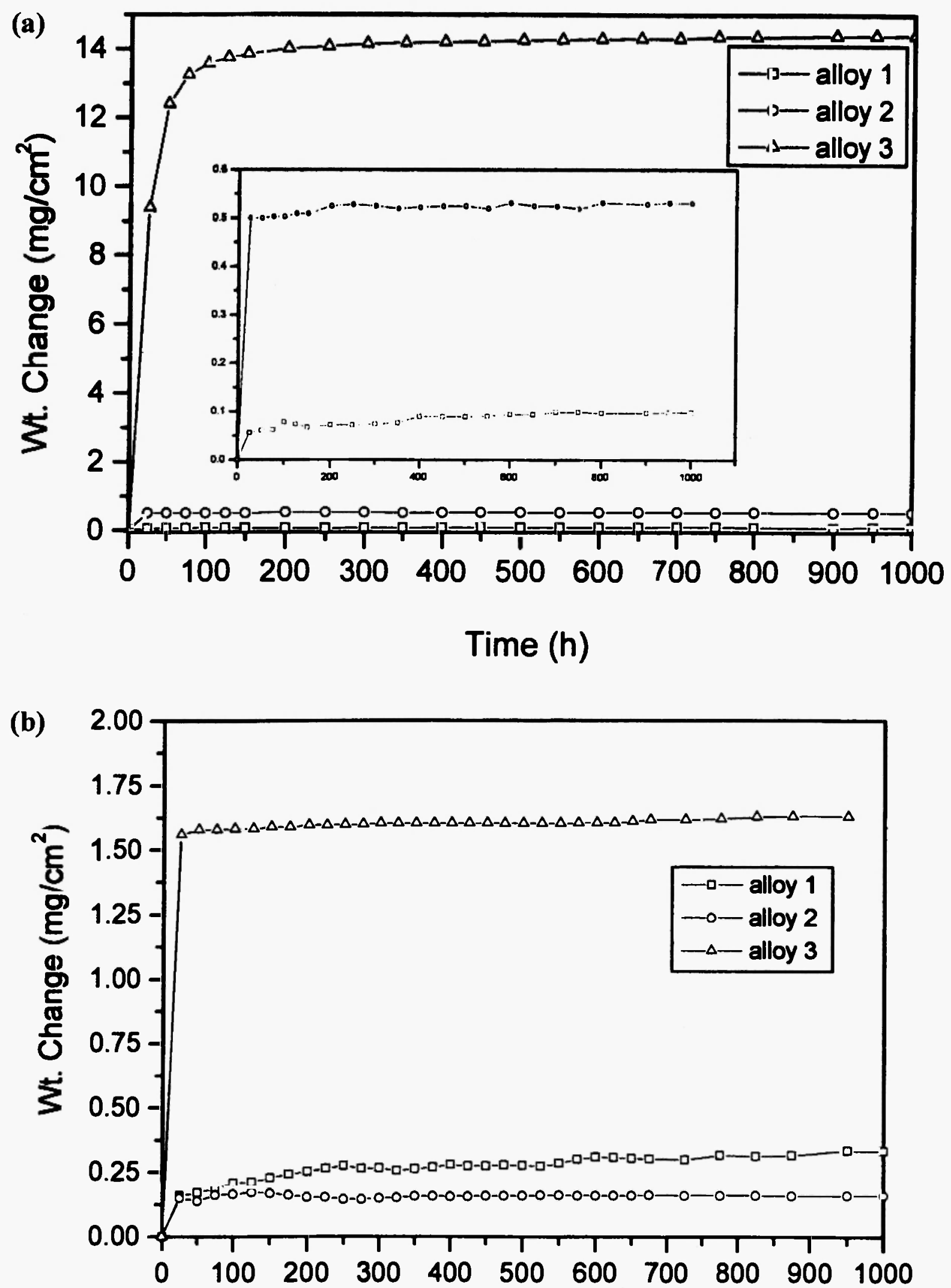

Time (h) continued... 

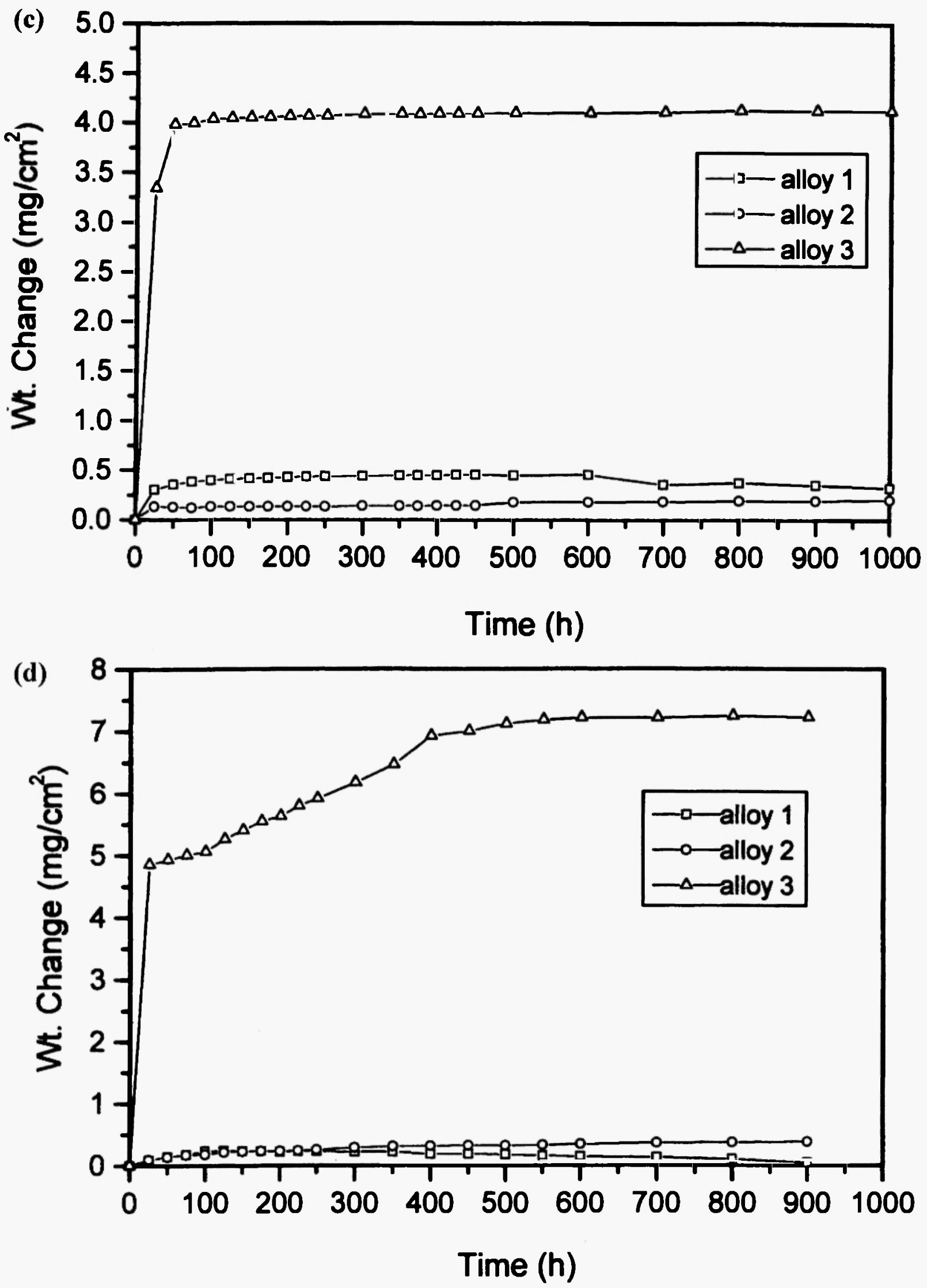

Fig. 3: Oxidation kinetics of alloys 1 to 3 at: a) 973 , b) 1073, c) 1173 , and d) $1273 \mathrm{~K}$ 


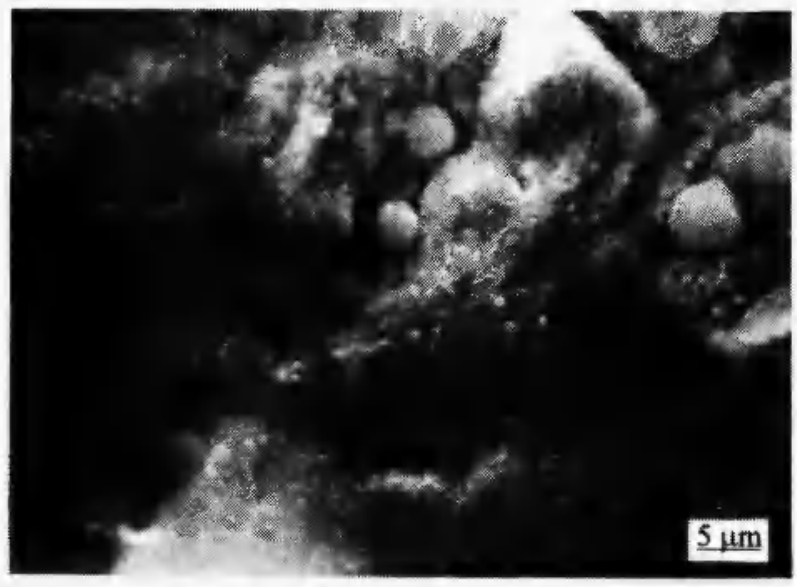

Fig. 4: SEM micrograph of alloy lafter oxidation at $1173 \mathrm{~K}$ for $1000 \mathrm{~h}$ shows formation of grooves between oxides.

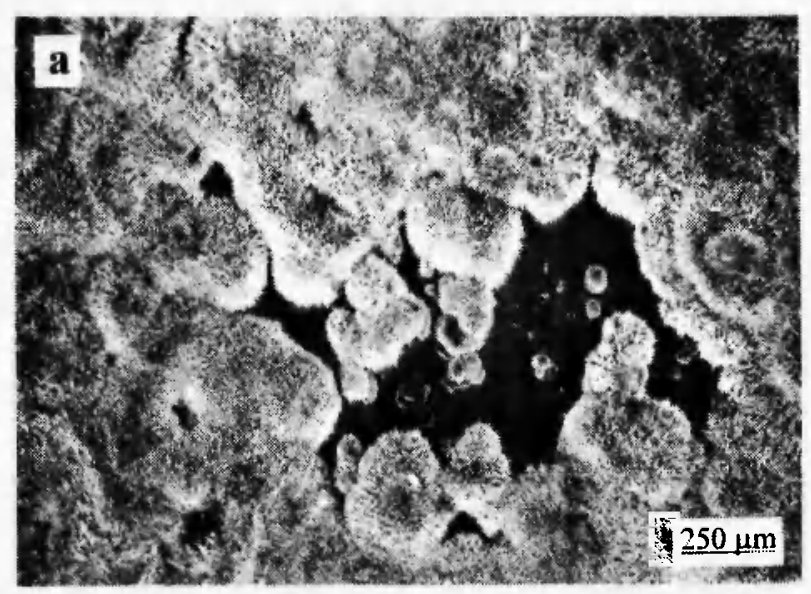

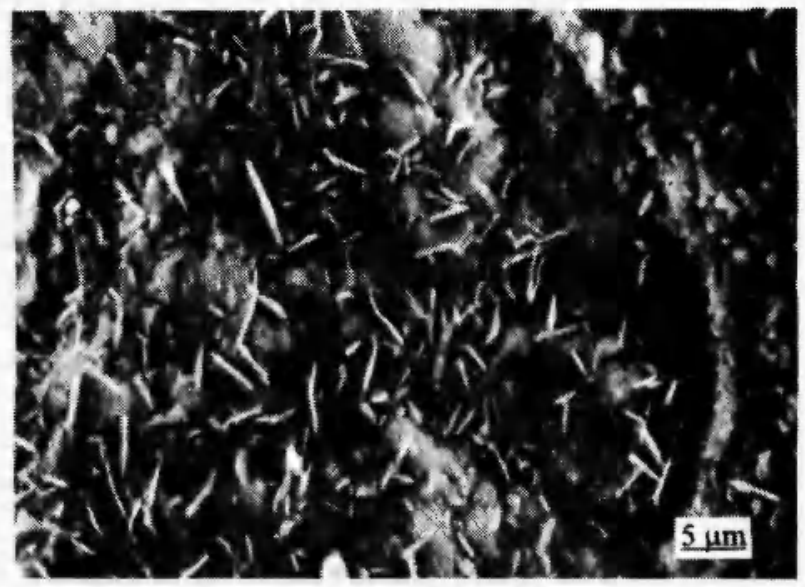

Fig. 5: SEM micrograph of alloy 2 after oxidation at $1273 \mathrm{~K}$ for $1000 \mathrm{~h}$ shows development of platelet like particles in the oxide scale.

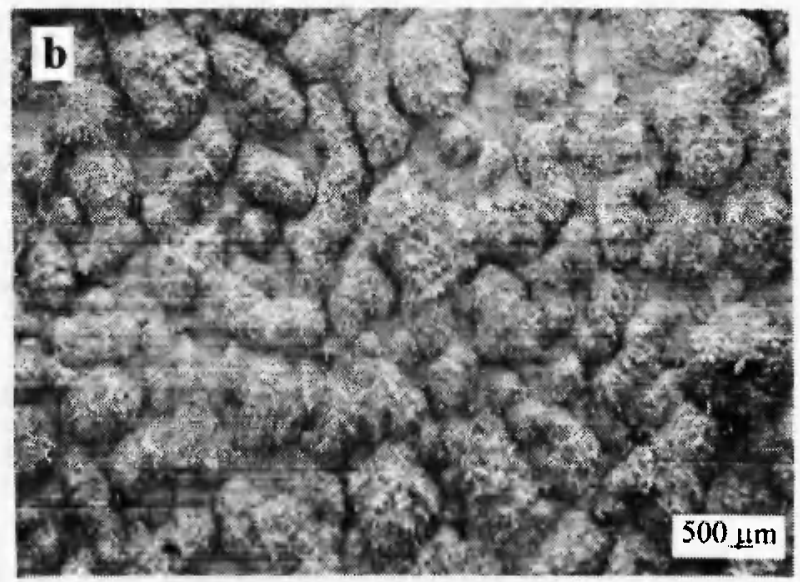

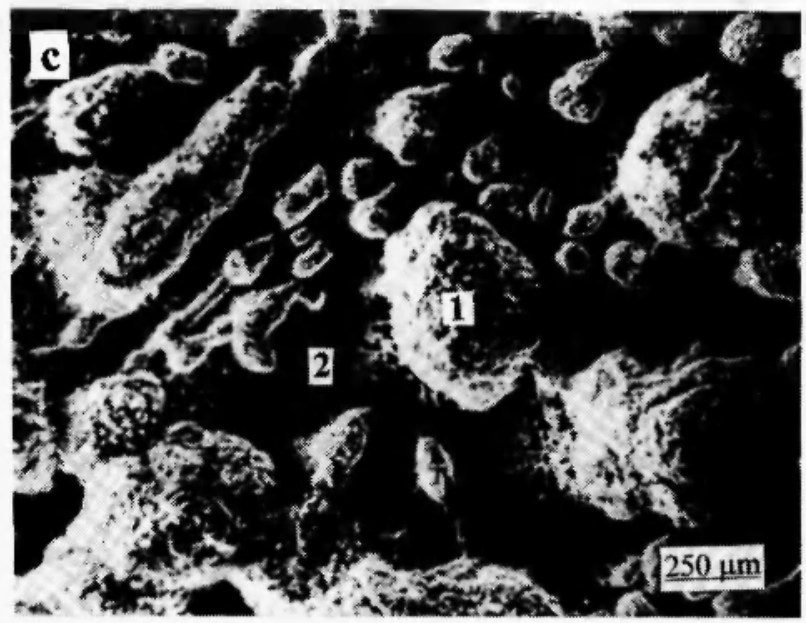

Fig. 6: SEM micrograph of alloy 3: a) after oxidation at $973 \mathrm{~K}$ for $100 \mathrm{~h}$, showing oxides in needle shape, b) after oxidation at $1173 \mathrm{~K}$ for $1000 \mathrm{~h}$ shows deeper attack on matrix in comparison with the carbide is shown and $\mathrm{C}$ ) after oxidation at $1273 \mathrm{~K}$ for $1000 \mathrm{~h}$ showing formation of oxide nodules on the surface. 


\section{Table 2}

EDX data of the oxide scale corresponding to locations1 and 2 as shown in Fig. $6 \mathrm{c}$.

\begin{tabular}{ccc}
\hline Location & $\mathrm{Al}(\mathrm{wt} \%)$ & $\mathrm{Fe}(\mathrm{wt} \%)$ \\
\hline 1 & 3.0 & 97.0 \\
2 & 32.0 & 68.0 \\
\hline
\end{tabular}

completely covered with oxide layer. Figure $6 \mathrm{~b}$ displays the morphology of the same alloy oxidized at $1173 \mathrm{~K}$ for $1000 \mathrm{~h}$. It shows that a few sites are deeply oxidized, which are likely to be the matrix (Fe-Al). A micrograph of the same alloy oxidized at $1273 \mathrm{~K}$ for $1000 \mathrm{~h}$ displays typical oxide nodules in Fig. 6c. Formations of these nodules are possibly due to breakaway oxidation (Fig. 3d). The data of EDX analysis carried out at these nodules and oxide layer is listed in Table 2. The result shows that these nodules are mainly formed of iron oxide, whereas the oxide surface is composed of mixed oxides of iron and $\mathrm{Al}$. The appearance of nodules, even in binary $\mathrm{Fe}-\mathrm{Al}$ alloys, is reported by Tomaszeewicz and Wallwork $/ 13 /$. The cross-sectional analysis of the oxide-scale showed the presence of some Al-oxide precipitates in iron oxide nodules formed after $1073 \mathrm{~K}$ for $100 \mathrm{~h}$ on $\mathrm{Fe}-6 \mathrm{Al}$.

A cross-sectional view of the oxide-scale as seen in SEM of alloy 2 oxidized at $1173 \mathrm{~K}$ for $1000 \mathrm{~h}$ is presented in Fig. 7. The micrograph reveals that the oxide-scale fell off from the substrate during polishing of the sample for cross-sectional analysis, which indicates poor adherence of the alumina scale with the base alloy. Despite the falling of oxide layer, this feature shows the higher oxidation tendency of the carbide phase compared to that of the matrix. Figure 8 shows the cross-sectional view of the oxide-scale of alloy 3 oxidized at $973 \mathrm{~K}$ for $1000 \mathrm{~h}$. The total thickness of the scale is $60 \mu \mathrm{m}$, in which two distinguished layers of oxides are visible. The inner layer of about $20 \mu \mathrm{m}$ appears compact and the outer layer of about $40 \mu \mathrm{m}$ is seen to be porous. Previous work related to the Fe-8AlIC alloy, under similar oxidation conditions, revealed the inner layer as aluminum oxide and outer layer as iron oxides $/ 13 /$. A sign of decarburization could be seen beneath the oxide scale. The formation of inner layer acts (aluminum oxide) as a healing layer, which

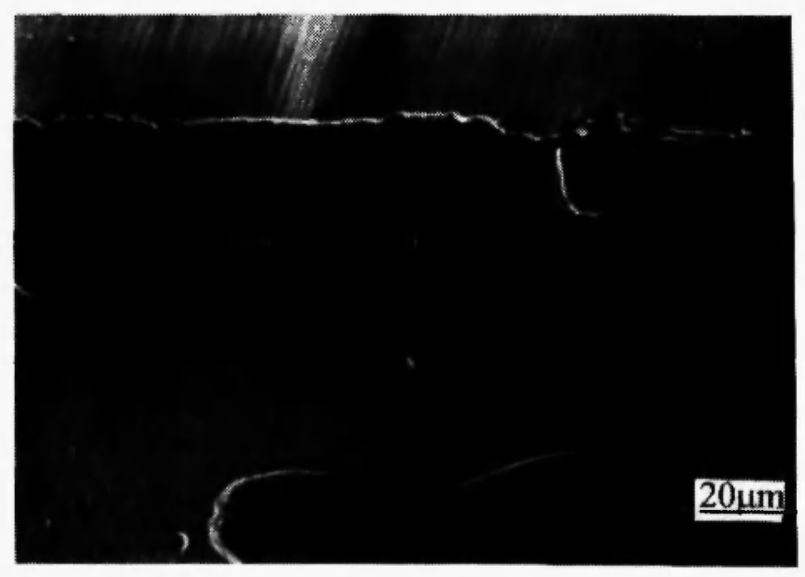

Fig. 7: Cross-sectional view of the oxide scale formed on alloy 2 at $1173 \mathrm{~K}$ after $1000 \mathrm{~h}$. Deeper attack on the carbide in comparison with the matrix is shown.

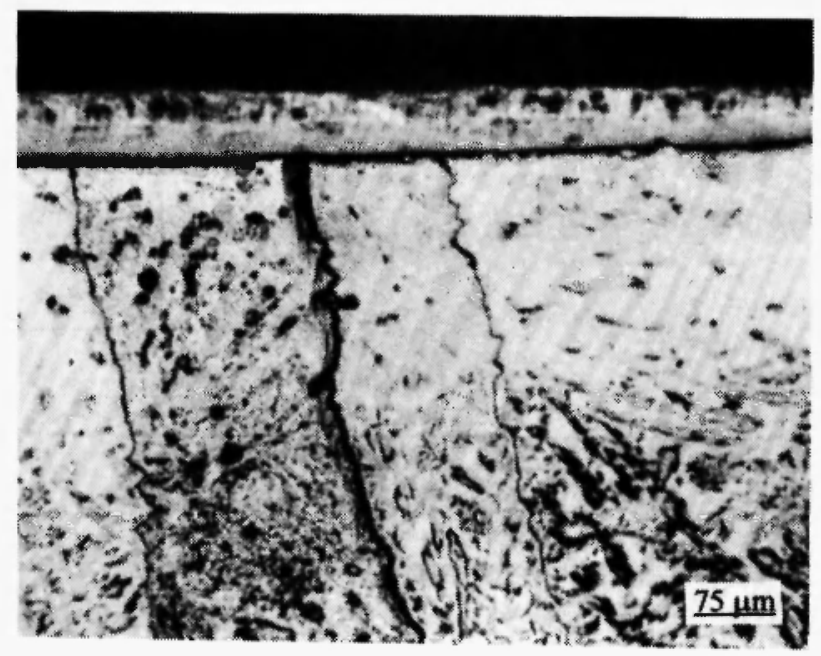

Fig. 8: Cross-sectional view of the oxide scale formed on alloy 3 at $973 \mathrm{~K}$ after $1000 \mathrm{~h}$, showing formation of two layers of oxide and decarburization under the scale.

prevents the alloy from further oxidation as well as decarburization.

The XRD patterns of the oxidized alloys were found to be rather similar to those of an earlier study /14/. On the whole, with an alloy having $16 \mathrm{wt} \% \mathrm{Al}$, the peaks correspond to $\propto-\mathrm{Al}_{2} \mathrm{O}_{3}$ and $\mathrm{Fe}_{3} \mathrm{Al}_{069}$, whereas with an alloy containing $8 \mathrm{wt} \% \mathrm{Al}$, peaks belonging to iron oxide, $\mathrm{Fe}_{2} \mathrm{O}_{3}$, were identified. 


\section{DISCUSSION}

Although, on decreasing the $\mathrm{Al}$ content from 16 to $10 \mathrm{wt} \%$, not much difference in the weight gain of the alloy could be observed, the occurrence of inversion of oxidation shifted from $1273 \mathrm{~K}$ to $1073 \mathrm{~K}$. A further reduction in the $\mathrm{Al}$ content to $8 \mathrm{wt} \%$ results in a marked increase in the inversion of oxidation as well as general oxidation behavior of the alloy. The critical concentration of $\mathrm{Al}$ required for oxidation resistance between 973-1273 K, in the present Fe-Al-0.5C alloys seems to be $10 \mathrm{wt} \%$, as change in $\mathrm{Al}$ content from 10 $w t \%$ causes an increase in oxidation tendency of the alloy. Notably, for a cast binary $\mathrm{Fe}-\mathrm{Al}$ alloy, critical $\mathrm{Al}$ concentration was reported to be approximately 16-19 at $\%$ at $1073-1173 \mathrm{~K} / 13 /$. Kinetics of the oxidation pattern of the present alloys are very similar to an earlier study, on the oxidation behavior of Fe-Al-1C alloys /14/. For a general discussion of the oxidation kinetics and mechanism of the present alloys the reader is referred to that study $/ 14 /$. However, the observable difference between these two is that the weight gain due to oxidation of the Fe-Al-0.5C alloys is lower than that of $\mathrm{Fe}-\mathrm{Al}-\mathrm{IC}$ alloys. This is because, in high carbon content alloys, the formation of a significant volume fraction of carbide precipitates lower the Al content in the matrix, thereby leading to poor resistance to oxidation. Kao and Wan have also reported the harmful effect of $\mathrm{C}$ on the oxidation behavior of Fe-5.5Al alloy as they found oxidation rate of $\mathrm{Fe}-5.5 \mathrm{Al}-0.55 \mathrm{C}$ alloy is higher than that of $\mathrm{Fe}-5 \mathrm{Al}$ alloy at $1073 \mathrm{~K} / 16 /$. It was suggested to be mainly due to the formation of iron oxide nodules in $\mathrm{C}$ containing alloys. A similar observation was also made by Boggs $/ 15 /$. However, in none of these studies has emphasis been placed on analyzing the two phases present in the alloy.

The present discussion is focused on the oxidation behavior of the carbide phase vs matrix. In order to understand the oxidation behavior of carbide and matrix phases their compositional difference was calculated, in Fe-16Al-1C alloy, by scanning Auger spectra analysis at both the phases, after complete removal of the oxide film by Ar ion sputtering (Figs. 9a-b). This investigation reveals that carbide phase has only 10 at $\% \mathrm{Al}$ (Fig. 9b)

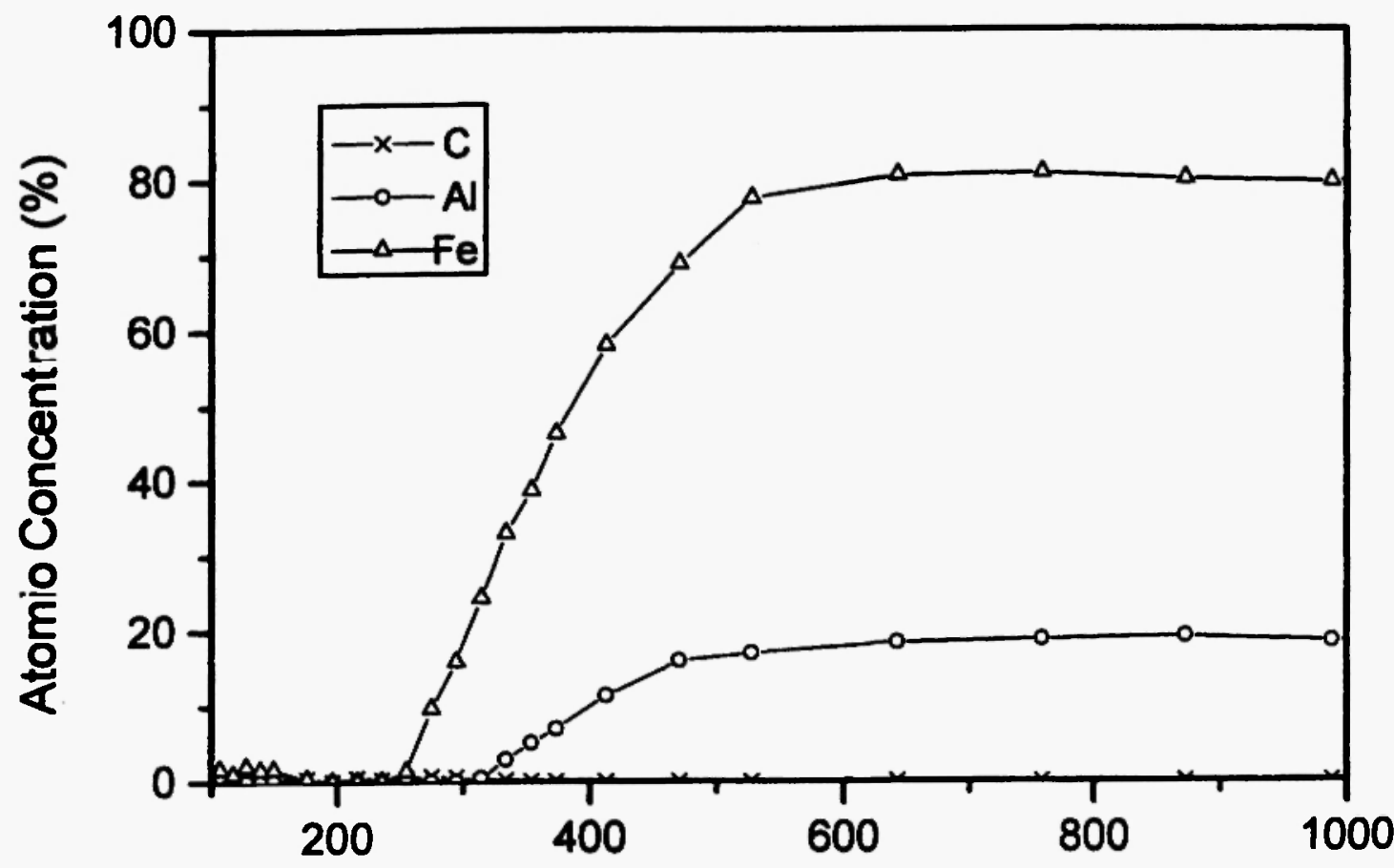

Sputter Depth (nm)

(a)

continued... 


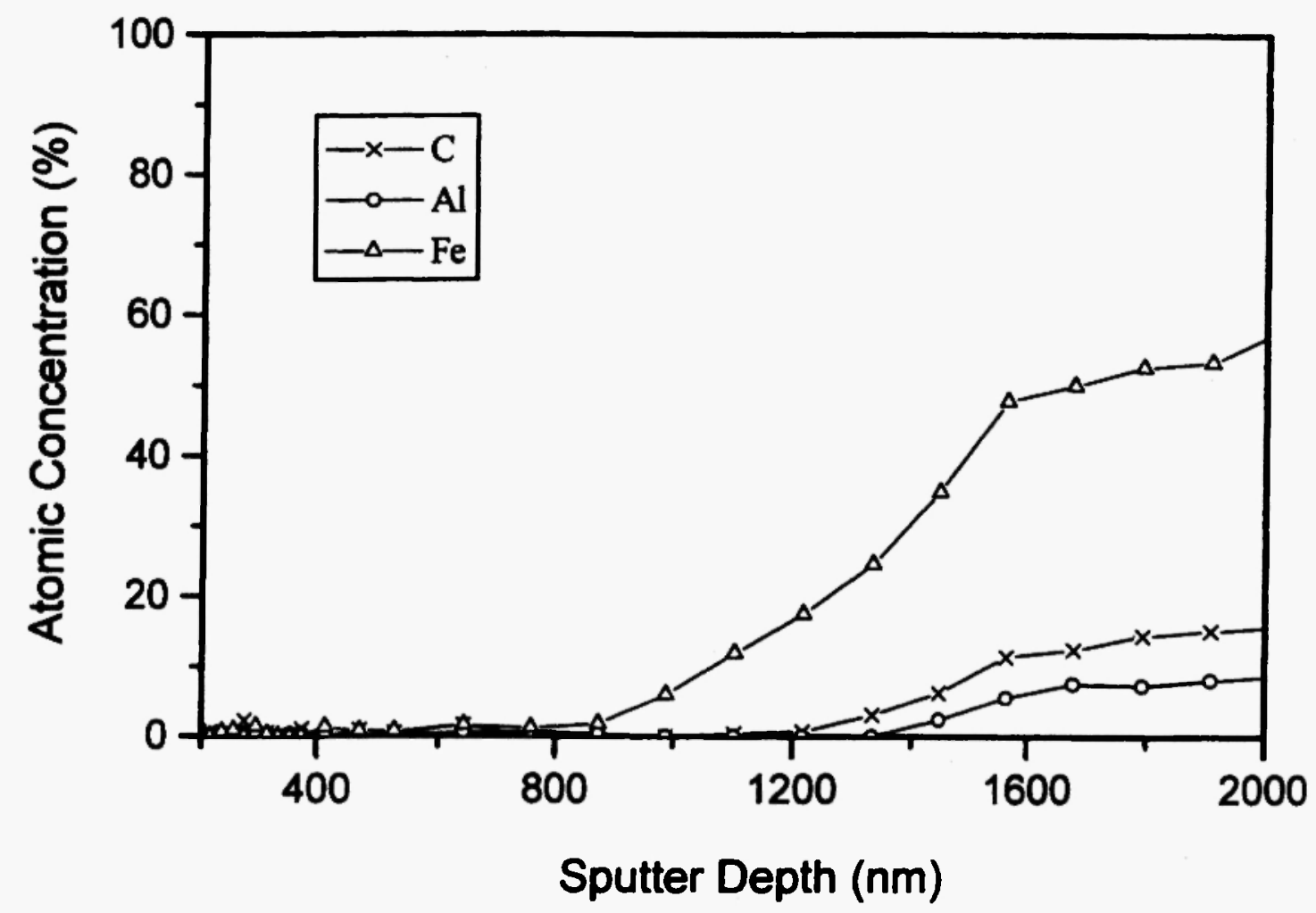

(b)

Fig. 9: AES depth profiles at: a) matrix and b) carbide phase

as compared to 17 at $\% \mathrm{Al}$ (Fig. 9a) in the matrix. Although the role of carbon in affecting the corrosion behavior of $\mathrm{Fe}_{3} \mathrm{AlC}_{0.69}$ is not clear, the fact that its $\mathrm{Al}$ content is lower than than $\mathrm{Fe}_{3} \mathrm{Al}$ phase makes the former more vulnerable to oxidation than the latter. Now it is necessary to examine what happens to the relative oxidation resistance of these phases, as the $\mathrm{Al}$ content of the alloy is gradually reduced, while keeping its carbon content the same. This aspect is brought out in the subsequent text by examining the vertical section of the Fe-Al-C phase diagram corresponding to $0.4 \mathrm{wt} \% \mathrm{C}$ (Fig. 10) which is close to the carbon content of the present alloys 123 . XRD studies show that the lattice parameter of $\mathrm{Fe}_{3} \mathrm{AlC}_{0.69}$ remains the same at $0.377 \mathrm{~nm}$ in all the alloys. Since lattice parameter of the carbide remains the same, the carbide is expected to retain its stoichiometry. Therefore, lowering of $\mathrm{Al}$ content in these alloys leads to depletion of $\mathrm{Al}$ content from the matrix in order to maintain the stoichiometry of the

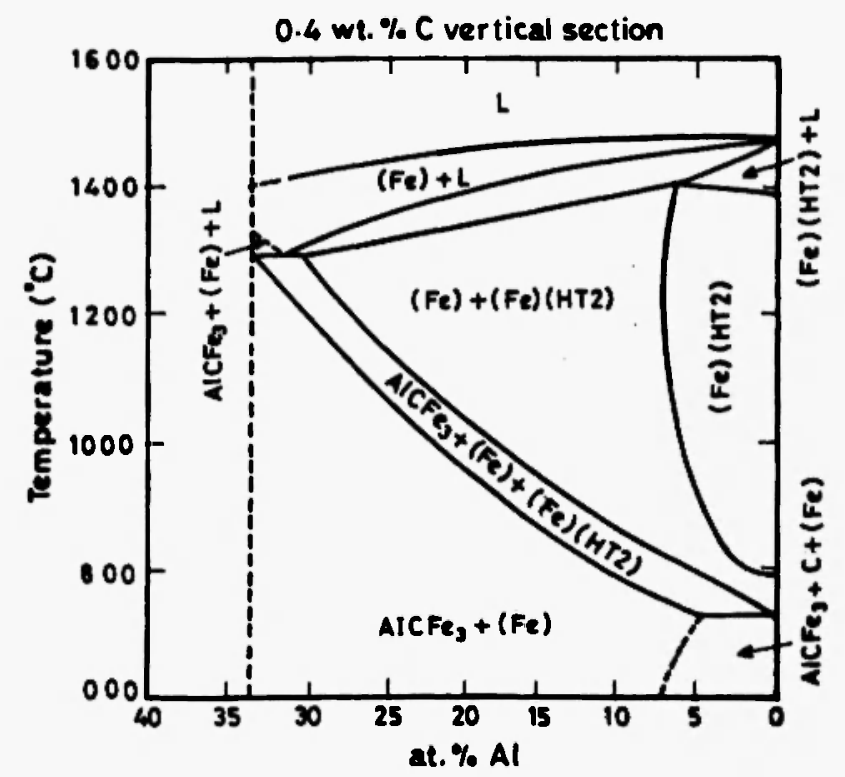

Fig. 10: Vertical section of the Fe-Al-C phase diagram at constant $\mathrm{C}$ content of $0.4 \mathrm{wt} \%$ 123\%. 
carbide. As the matrix is left with less $\mathrm{Al}$, all those carbons present in the alloy, in excess of their solubility in $\mathrm{Fe}-\mathrm{Al}$ phase, combine to form $\mathrm{Fe}_{3} \mathrm{AlC}_{0.69}$ phase. At this stage $\mathrm{Al}$ content in both the phases is nearly the same. Thus there is a possibility of oxidation resistance of carbide phase becoming comparable to that of the matrix phase as it is in the case of alloy 2. Moreover, due to the similar oxidation tendency of both the phases it avoids the mismatch between the oxide layers formed on both the phases and provides a more uniform oxide layer to overall surface of the alloy. This could be a plausible explanation for the oxidation tendency of alloy 2 being lower than that of alloy 1 at temperatures of 1073 and $1173 \mathrm{~K}$ despite the former having lower $\mathrm{Al}$ content than the latter. A further reduction in the $\mathrm{Al}$ content (to $8 \%$ ) causes a marked depletion of $\mathrm{Al}$ content from the matrix and it becomes more prone to oxidation compared to its carbide phase and overall oxidation behavior of this alloy is dominated by FeAl phase, which explains the oxidation behavior of alloy 3 . Additional microscope evidence for the higher oxidation tendency of matrix ( $\mathrm{Fe}-\mathrm{Al}$ ) than $\mathrm{Fe}_{3} \mathrm{AlC}_{0.69}$ arises from the SEM photograph in Fig. 6b, where the matrix (Fe$\mathrm{Al}$ ) is predominately oxidized compared to that of the $\mathrm{Fe}_{3} \mathrm{AlC}_{0.69}$.

Besides the compositional difference between $\mathrm{Fe}_{3} \mathrm{AlC}_{0.69}$ and $\mathrm{Fe}_{3} \mathrm{Al} / \mathrm{FeAl}$ their difference in thermal stability at the oxidizing temperatures also affects the overall oxidation behavior of these materials. Lower oxidation tendency of alloy 1 at $1273 \mathrm{~K}$ compared to that at $1173 \mathrm{~K}$ is attributed to dissolution of carbide phase at higher temperature /18/ and not to any phase transformation in $\mathrm{Al}_{2} \mathrm{O}_{3} / 14 /$. Notably, in alloy 2 no such inversion of oxidation is observed at $1273 \mathrm{~K}$. This can be explained by the fact that, despite dissolution of the carbide phase in the matrix phase, the overall $\mathrm{Al}$ content in alloy 2 is much lower than alloy 1 , to provide a protective alumina layer on the surface at $1273 \mathrm{~K}$. This causes oxidation of $\mathrm{Fe}$ and hence there is a continuous increase in weight gain (Fig. 3d). The oxide morphology of the scale at this temperature further substantiates this fact as it shows formation of some iron oxides in the form of platelet-like crystals (Fig. 5). It is worth mentioning that alloys 1 and 2 do not suffer from decarburization, which is mainly attributed to the formation of protective alumina layer on the surface during oxidation $/ 21 \%$.

Reducing the $\mathrm{Al}$ content down to 8-wt\% not only causes a marked increase in the weight gain but the alloy also results in decarburization. More interestingly, though the alloy suffers from decarburization at $973 \mathrm{~K}$ (Fig. 8), it is free from decarburization at $1073 \mathrm{~K}$. Contrary to this, Kao and Won have reported no carbide free layer under the oxide-metal interface at $873 \mathrm{~K}$, whereas at a higher temperature $(1073 \mathrm{~K})$ there was a carbide free zone in Fe-5.5Al-0.55C alloy. According to them, $\mathrm{CO} / \mathrm{CO}_{2}$ is formed by the carbon atoms produced by the decomposition of carbide at $1073 \mathrm{~K}$ and oxygen diffusing in from outside may diffuse out via pores and microcracks in the scale. Notably, these authors have not reported any inversion in oxidation between 873$1273 \mathrm{~K}$. Therefore, the absence of decarburization in the present study at $1073 \mathrm{~K}$ seems to be closely related to the inversion of the oxidation as it promotes the formation of a more protective uniform alumina layer through which inward diffusion of oxygen becomes difficult.

Figure 11 shows the schematic diagram for the development of oxide layer on carbide and matrix phases in Fe-Al-C alloys, and their stability during oxidation, based on the above discussion. The various sequences taking place at different oxidation temperatures are explained through this model.

\section{CONCLUSIONS}

1. In high-Al content alloys, carbide phase is less resistant to oxidation, whereas in low-Al content alloys it is the matrix phase.

2. In high-Al content alloys, inversion of the oxidation at $1273 \mathrm{~K}$ is related to the dissolution of carbide phase, whereas the inversion of the oxidation in low$\mathrm{Al}$ content alloys at $1073 \mathrm{~K}$ is associated with enrichment of $\mathrm{Al}$ in the oxide phase.

3. Addition of carbon to iron aluminides, required for enhancing the high temperature strength should be as low as possible. As carbides are more prone to oxidation. 


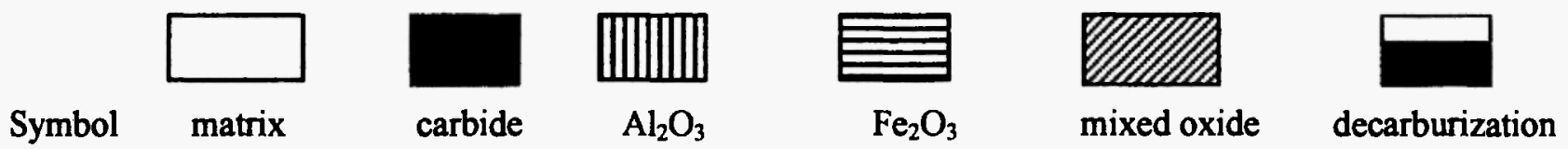

\section{Alloy 1 (Fe-16Al-0.5C)}

$973 \mathrm{~K}$

$1073 \mathrm{~K}$

$1173 \mathrm{~K}$

$1273 \mathrm{~K}$
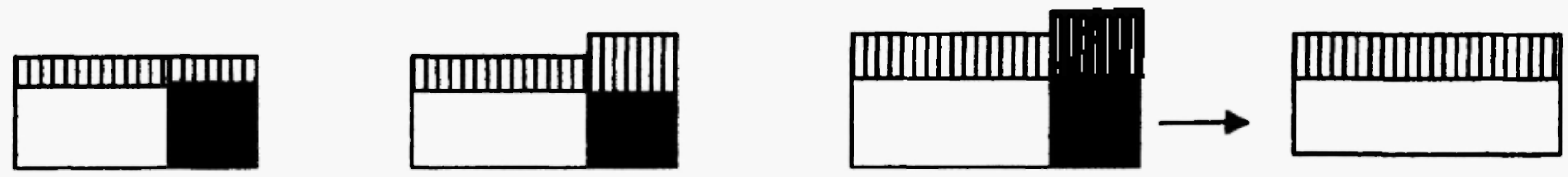

inversion of oxidation

Alloy 2 (Fe-10Al-0.5C)

$973 \mathrm{~K}$

$1073 \mathrm{~K}$

$1173 \mathrm{~K}$

$1273 \mathrm{~K}$
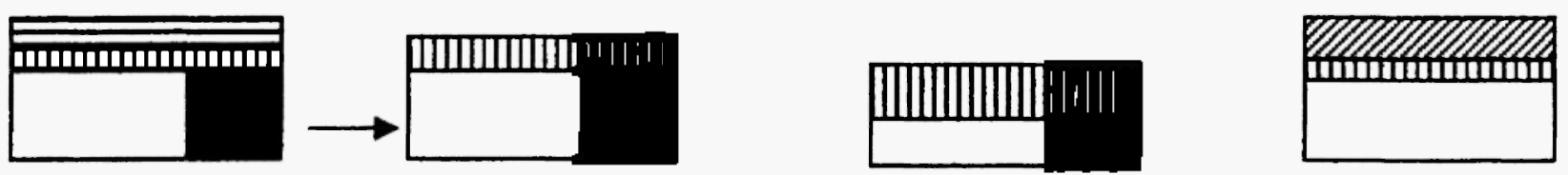

inversion of oxidation

Alloy 3 (Fe-8Al-0.5C)

$973 \mathrm{~K}$

$1073 \mathrm{~K}$
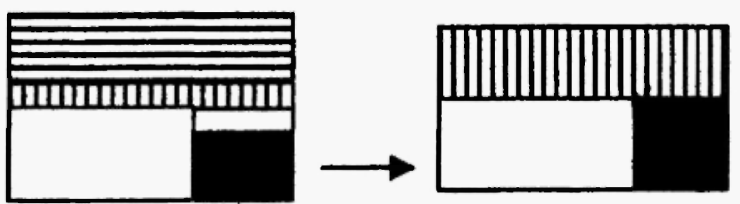

$1173 \mathrm{~K}$

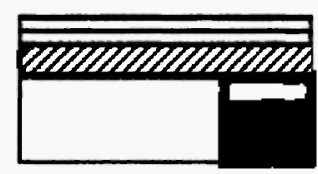

$1273 \mathrm{~K}$

nodules,

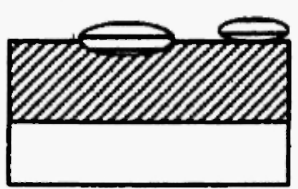

inversion of oxidation

Fig. 11: Schematic diagram of the oxidation of Fe-Al-C alloys 


\section{ACKNOWLEDGMENTS}

The project has been funded by DRDO, Government of India. The authors thank Dr. R.G. Baligidad for providing the materials and Dr. D. Banerjee, Director, Defence Metallurgical Research Laboratory for his keen interest in this work.

\section{REFERENCES}

1. R.G. Baligidad, U. Prakash, A. Radhakrishna, V. Ramakrishna Rao, P.K. Rao and N. B. Ballal, Scr. Mater. 36, 667 (1997).

2. R.G. Baligidad, U. Prakash, A. Radhakrishna, V. Ramakrishna Rao, P.K. Rao and N.B. Ballal, Scr. Mater. 36, 105 (1997).

3. R.G. Baligidad, U. Prakash, V. Ramakrishna Rao, P.K. Rao and N.B. Ballal, ISIJ Int. 36, 1448 (1996).

4. A. Radhakrishna, R.G. Baligidad and D.S. Sharma, Scr. Mater. 45, 1077 (2001).

5. K.S. Kumar and L. Pang, Mater. Sci. Eng. A258, 153 (1998).

6. L. Pang, and K.S. Kumar, Mater. Sci. Eng. A258, 161 (1998).

7. C. G. McKamey, C. G. DeVan, J. H. Tortorelli and V.K. Sikka, J. Mater. Res. 6, 1779 (1991).

8. W. R. Kerr, Metall. Trans., 17A, 2298 (1986).

9. P.F. Tortorelli and K. Natesan, Mater. Sci. Eng. A258, 115 (1998).
10. P.F. Tortorelli and J.H. De Van, Mater. Sci. Eng. A153, 573 (1992).

11. I. Kim, W.D. Cho and H.J. Kim, J. Mater. Sci. 35, 4695 (2000).

12. N. Babu, R. Balasubramaniam and A. Ghosh, Corros. Sci. 43, 2239 (2001).

13. P. Tomaszewicz and G.R. Wallwork, Oxid. Met. 19, 165 (1983).

14. V. Shankar Rao, R.G. Baligidad and V.S. Raja, Intermetallics 10, 73 (2002).

15. William E. Boggs, J. Electrochem. Soc. 118, 906 (1971).

16. C.H. Kao and C.M. Wan, J. Mater. Sci. 22, 3203 (1987).

17. C.H. Kao and C.M Wan, J. Mater. Sci. 23, 1943 (1988).

18. V. Shankar Rao, V.S. Raja and R.G. Baligidad, Oxid. Met. 57, 449 (2002).

19. R.G. Baligidad, U. Prakash, V. Ramakrishna Rao, P.K. Rao and N.B. Ballal, Iron Making Steel Making, 21, 324 (1994).

20. R.G. Baligidad, U. Prakash. V. Ramakrishna Rao, P.K. Rao and N.B. Ballal, ISIJ Int. 35, 443 (1995).

21. R.G. Baligidad and A. Radhakrishna, Mater. Sci. Eng. A283, 211 (2000).

22. T. B. Massalaki, Binary Alloy Phase Diagrams, Second Edition, Vol. 1, ASM Metals Park, $\mathrm{OH}$, 1990; p. 112.

23. P. Villars, A. Prince, and H. Okamoto, Handbook of Ternary Alloy Phase Diagrams, Vol. 3, ASM Metals Park, OH, 1990; p.2850. 